\title{
Emojis e Hashflags: uma análise sóciorretórica da linguagem multissemiótica do Twitter
}

\section{Emojis and Hashflags: a socio-rhetorical analysis of the 'Twitter's multi- semiotic language}

\author{
Elisa Mattos ${ }^{1}$ \\ Vanessa Brasil ${ }^{2}$ \\ Gustavo Garcia ${ }^{3}$ \\ Nivia Aniele Oliveira ${ }^{4}$
}

DOI: $10.28998 / 2317-9945.2019 n 63 p 47-69$

\section{Resumo}

Este artigo apresenta uma análise de emojis mapeados em 15 tuites, nos quais a confluência de modos semióticos é primordial para a construção de sentido, para a organização sóciorretórica do gênero discursivo microblog e para a escolha dos emojis. Considerando os pressupostos teóricos de Conole e Dyke (2004), Kress (2010), Kress e van Leeuwen (2006) e Danesi (2017), os tuites foram analisados e os emojis foram categorizados segundo Danesi (2017). A análise revela que, nos tuites examinados, os emojis são empregados em três funções: sintática, como pontuação; semântica, substituindo itens lexicais; e enfática, como marcadores discursivos. A análise também identificon a presença de hashflags, um novo tipo de hashtag da qual emojis customizados são acionados. Nas hashflags dos tuites analisados, os emojis atuam como indice simbólico do conteúdo semântico-pragmático da hashtag, evidenciando a interdependência entre os modos semióticos constitutivos dos tuites, bem como a dinamicidade das affordances do ambiente digital.

Palavras-chave: Emojis. Modos semióticos. Tuite. Hashflag. Affordance

\begin{abstract}
This paper presents an analysis of emojis mapped in 15 tweets, in which the confluence of semiotic modes is seen as the foundation for meaning construction, for the socio-rhetorical structure of the genre microblog and for the choice of emojis used in the tweets. Based on the theoretical assumptions of Conole and Dykee (2004), Kress (2010), Kress and van Leeuwen (2006) and Danesi (2017), the tweets were analyzed and the emoji were categorized according to Danesi (2017). The analysis reveals that, in the tweets examined, the emojis have been employed according to three functions: syntactic, as punctuation marks; semantic, replacing lexical items; and emphatic, as discourse markers. The analysis also identified hashflags, a new type of hashtag from which custom emojis are triggered. In the hashflags present in the analyzed tweets, the custom emojis act as a
\end{abstract}

\footnotetext{
${ }_{1}$ Mestre em Didática de Inglês pela Universidade NOVA de Lisboa. Mestranda em Linguística Aplicada e professora de Inglês para Fins Acadêmicos na Universidade Federal de Minas Gerais.

${ }_{2}^{2}$ Mestranda em Linguística Aplicada na Universidade Federal de Minas Gerais.

${ }^{3}$ Mestrando em Linguística Aplicada e professor de Inglês para Fins Acadêmicos na Universidade Federal de Minas Gerais.

${ }^{4}$ Mestre e Doutoranda em Linguística Teórica e Descritiva pela Universidade Federal de Minas Gerais. Professora de espanhol do Instituto Federal de Brasília.
} 
symbolic index of the semantic-pragmatic content of the hashtag, thus revealing the interplay between the semiotic modes in the tweets and the dynamic nature of the digital affordances.

Keywords: Emojis. Semiotic modes. Tweet. Hashflag. Affordance

Recebido em: 16/02/2019.

Aceito em: 19/03/2019.

\section{Introdução}

A importância dos estudos sobre gêneros digitais tem se tornado cada vez mais visível com a crescente adesão a textos majoritariamente imagéticos (cf. DANESI, 2017) oriundos da Internet. Segundo McCay-Peete e Quan-Haase (2017), a comunicação digital está se ancorando cada vez mais na linguagem pictórica. Um exemplo são os textos curtos e altamente imagéticos dos microblogs, concentrados principalmente na imagem em forte conexão com outros modos semióticos, em uma confluência de semioses que navegam na hipermobilidade e fluidez das tecnologias digitais - de áudio e vídeo a gifs e emojis.

Considerando a multimodalidade constitutiva dos microblogs, cujos textos se ancoram em grande parte na imagem e escrita, invariavelmente com o auxílio de elementos digitais, este artigo analisa emojis mapeados em 15 tuítes com base nos pressupostos teóricos da sociossemiótica (KRESS, 2010; KRESS; VAN LEEUWEN, 2006) em associação às convenções sóciorretóricas do gênero discursivo microblog (ZAPPAVIGNA, 2012) e às affordances do ambiente digital (cf. CONOLE; DYKE, 2004). A categorização dos emojis, por seu turno, seguiu a proposta de Danesi (2017).

\section{Modos semióticos: a imagem}

Segundo Kress (2010) e Kress e van Leeuwen (2006), modos semióticos são recursos de criação de sentido motivados cultural e socialmente, que oferecem diferentes potenciais de significação, a depender de como são utilizados na comunicação. Fala, escrita, gestos e imagem são exemplos de modos semióticos, cujas características são construídas e (re)modeladas na interação social e, tanto os modos quanto sua materialização nas práticas discursivas tendem a variar sócio-historicamente, de cultura para cultura, em observação também feita por Jewitt (2013) e Danesi (2017).

A imagem como modo semiótico é muito diferente da fala e da escrita, por não operar com as mesmas unidades desses sistemas (fonemas, morfemas etc.) e por ter como suporte a noção de espaço (KRESS, 2010). Os sentidos construídos pela imagem advêm da combinação de elementos próprios desse modo semiótico, tais como cores e formas espaciais. Um exemplo cotidiano são as placas de trânsito. Utilizadas mundialmente, elas em

\footnotetext{
${ }^{5}$ Optamos pelo termo gênero discursivo por acreditarmos que essa noção de gênero, fundamentada em Bakhtin (1997), aproxima-se mais da perspectiva sócio-retórica de vários dos autores a quem recorremos, como Miller (2015) e Jewitt (2013). Como nota Bezerra (2017), essa distinção ocorre em função da polissemia do item lexical gênero. No inglês, por exemplo, variações teórico-metodológicas associadas à expressão partem da linha de análise de cada teórico, não necessitando ser explicitadas pelo uso de adjetivo modificador, tal como se faz no português para gênero discursivo e gênero textual.
} 
geral fazem amplo uso da associação entre palavras (modo semiótico da escrita) e cor e forma (modo semiótico da imagem). Além disso, exigem interpretação de sua totalidade, ou seja, pela soma do conjunto de modos semióticos, para que o propósito comunicativo do gênero e a mensagem veiculada possam ser alcançados, considerando-se seu contexto de produção.

Para ilustrar esse raciocínio, apresentamos a figura 1 , em que a cor vermelha ${ }^{6}$ significa alerta, nesse contexto, e a palavra dur significa pare. A posição físico-geográfica da placa, em uma esquina no interior da Turquia, associada à representação visual e aos significados desses recursos semióticos são pistas para o leitor interpretar a mensagem pretendida e, dessa leitura, realizar determinadas ações. O formato da placa também orienta a compreensão, desde que o leitor a reconheça como parte de seus conhecimentos prévios sobre o gênero em questão, em termos de sua forma e função.

Figura 1: placa de trânsito no interior da Turquia.

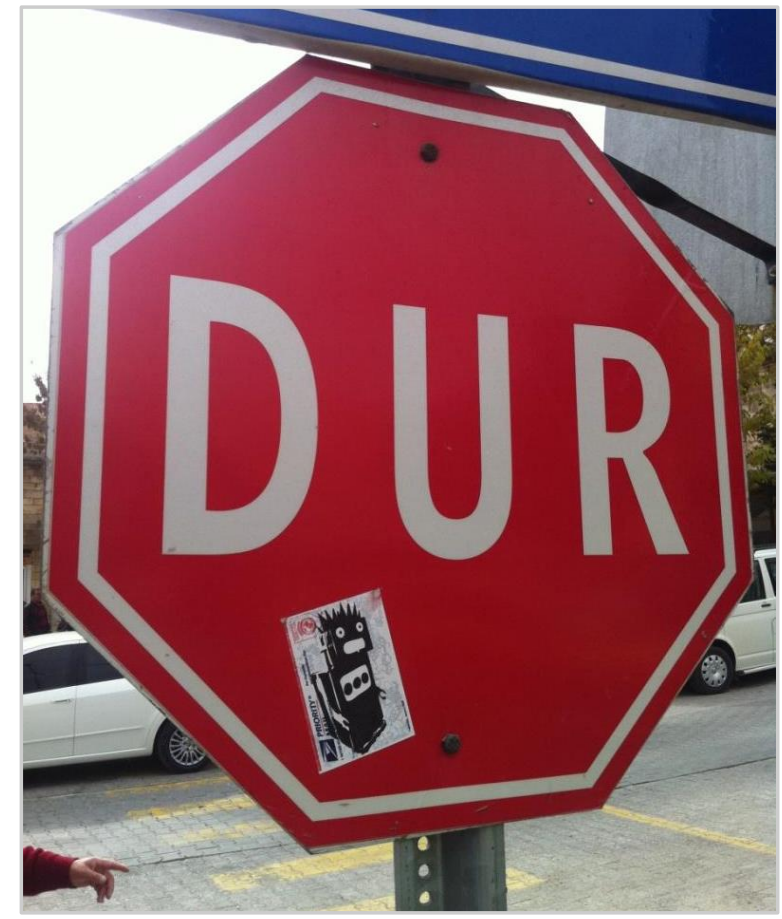

Fonte: acervo dos autores.

É interessante notar um detalhe um tanto anômalo na placa de trânsito: o adesivo de um robô, adicionado em algum momento após a instalação da placa. Em termos semióticos, o adesivo tornou-se parte da sinalização, mas não altera ou interfere em seu significado/função principal, já que a proporção de espaço entre a placa e o adesivo possibilita sua coexistência, isto é, um não obstrui a expressão e o significado do outro. Essa é uma observação importante, já que, como veremos, a inserção de emojis nos tuítes é possível devido às affordances digitais e configurações sócio-retóricas do gênero discursivo microblog, que se compõe de e aceita vários modos semióticos, sem que um atrapalhe o outro - pelo contrário, eles se complementam.

\footnotetext{
${ }^{6}$ Uma discussão sobre o simbolismo das cores pode ser encontrada em Kress e van Leeuwen (2002).
} 


\section{Affordances do ambiente digital}

De acordo com Gibson (2015), a noção affordance foi conceitualmente introduzida pela Psicologia para se referir ao que o ambiente oferece ao animal, para bem ou mal, em uma relação simbiótica. O conceito também foi explorado na área de Design, especificamente por Norman $(1988,1990)$, para quem as affordances descrevem o que os artefatos materiais, como as mídias tecnológicas, possibilitam a seus usuários. Na área tecnológica, Gaver (1996) conecta a expressão às interações sociais, nas chamadas social affordances e communicative affordances, termos mais usados nas pesquisas em mídias sociais. Ao revisarem esse conceito, Bucher e Helmond (2017) destacam seu caráter multivalente, o que igualmente se aplica às tecnologias digitais. Com Kress (2010) e Kress e van Leeuwen (2006), especificamente, a sociossemiótica coloca em foco a dinamicidade das affordances dos modos semióticos, isto é, as possibilidades (e limitações) de cada modo, enfatizando o caráter complementar dos recursos semióticos.

Entre as affordances do ambiente digital, como refletidas em Conole e Dyke (2004), observamos a multimodalidade e não-linearidade na combinação de modos semióticos e na disposição dos elementos linguísticos verbais e não verbais nos tuítes, além da acessibilidade a milhares de produções textuais abertas ao universo leitor da Internet. Percebemos também a velocidade das mudanças nesse gênero, as quais, embora pequenas, evidenciam o que Barton e Lee (2013) argumentam: nossas práticas escritas atuais são um reflexo do que as affordances e as tecnologias digitais nos oferecem. Por fim, destacamos o imediatismo, listado em Conole e Dyke (2004), que parece permear relações sociais e produções linguísticas online.

Por serem fundamentalmente multissemióticos, os gêneros digitais tendem a expandir o conjunto de potencialidades advindas de seus modos semióticos, em parte devido ao uso em massa das mídias sociais e à natureza altamente mutável da Internet (JEWITT, 2013). Miller (2015) afirma que essa dinamicidade é tanto efeito das affordances como de nossas interações com elas. Assim, a interdependência entre suporte e gênero discursivo digital (ASKEHAVE; NIELSEN, 2005) sugere que as affordances do microblog são reflexo das possibilidades digitais e interacionais do Twitter, que alimentam e viabilizam as estruturas sociorretóricas do gênero, em resposta a demandas comunicativas daqueles que o utilizam.

\section{Twitter: gênero discursivo digital e rede social}

Para entender melhor o gênero discursivo microblog é preciso primeiro localizá-lo nas mídias sociais, definidas como serviços da $W e b$ que permitem feedback instantâneo do público a que se destinam (RAMALHO, 2010). Através de conteúdo de fácil acesso criado, cocriado, modificado e compartilhado por usuários, as mídias sociais possibilitam colaboração, conexão e interação (McCAY-PEETE; QUAN-HAASE, 2017) e estão em atualização contínua. Quanto mais interagimos online, alimentando-as, mais mudanças elas estão suscetíveis a sofrer, sejam essas novidades geradas por nossas interações, seja pela criação de novas funcionalidades nesses espaços virtuais. Essa dinâmica se estende aos gêneros digitais, que também sofrem mudanças contínuas e têm fronteiras conceituais e funcionais um tanto quanto liquefeitas.

Como gênero discursivo digital e rede social, na qual usuários publicam textos curtos em sequência cronológica, os microblogs carregam traços sóciorretóricos dos blogues, de redes 
sociais e de serviços de mensagens instantâneas (ORIHUELA, 2007), mostrando-se híbridos e apresentando quesitos análogos aos blogues, entre eles o estilo informal, a presença de vários tipos de semioses, o texto livre e a comunicação interpessoal (MARCUSCHI, 2004). Por essas razões, os microblogs estão propensos à alta interatividade dos usuários, cujos projetos de dizer podem se centrar em uma miríade de modos semióticos, em constante fluxo de comunicação, característica apontada por Schmidt (2014) como mais específica do Twitter. Diferentemente dos blogues, no entanto, os microblogs têm na brevidade seu elemento-chave, no que se refere ao comprimento das mensagens, como o próprio nome indica.

Entre suas próprias convenções discursivas e estruturas sóciorretóricas (cf. MILLER, 2015), destacamos três marcadores básicos empregados no Twitter, quais sejam: a) o sinal de @ para mencionar outros usuários, direcionando explicitamente um micropost a outrem; b) a função RT - retweet ${ }^{7}$, para republicar tuítes de outros usuários, reproduzindo-os na íntegra e preservando a autoria original; e c) o símbolo de "jogo da velha" \# para "rotular" o assunto do tuíte. A primeira convenção marca a conta do usuário com o símbolo @, como um marcador dêitico, enquanto a segunda marca a projeção gramatical (ZAPPAVIGNA, 2012). O caractere \# é a anotação de tópico do tuíte (ZAPPAVIGNA, 2012) e, em termos computacionais, é o que permite o rastreamento de outras mensagens com a mesma hashtag.

Um efeito típico do microblog em outros meios de comunicação é o back channel, em que tuítes aparecem na tela da televisão/computador, em noticiários ou durante programas de auditório (ZAPPAVIGNA, 2012). Um exemplo típico de back channel são os quadros em que celebridades leem tuítes maldosos ou respondem a perguntas dos fãs feitas no Twitter. Essa interação com outros meios é um indicativo do alcance do Twitter, e de como as mídias sociais e gêneros digitais se infiltraram em nossas mais rotineiras práticas sociais.

\section{O papel das hashtags}

As propriedades digitais da etiqueta computacional hashtag permitem o rastreamento de dados e o mapeamento de conteúdo, em que a dimensão de alcance da hashtag depende do volume de compartilhamentos. As mais usadas são catalogadas por localidade nos Trending Topics (TT) e podem ser visualizados global ou regionalmente por um curto período. Apesar de efêmeras, as hashtags tornaram-se um modo de trazer vozes externas para um tuíte, em um processo chamado por Zappavigna (2012) de companheirismo intensificado. Por essa ótica, a troca rápida de tuítes baseada em hashtags pode ser encarada sócio-culturalmente como uma oportunidade de comunhão entre usuários e não apenas como uma comunicação randômica de ideias, proporcionando insights sobre a vida cotidiana.

Como exemplos, citamos os movimentos \#metoo e \#timesup, nos Estados Unidos, e a visibilidade de \#eudomestica na discussão sobre inclusão social no Brasil, os quais vão além da necessidade de engajamento entre usuários. Ao tocarem em questões muitas vezes ainda não discutidas na esfera pública, condensando o conteúdo em no máximo 280 caracteres, os tuítes alcançam milhões de usuários a um só tempo e oferecem uma oportunidade de troca rápida de experiências, criando um público para mundos (mais ou menos) privados. Assim,

\footnotetext{
${ }^{7}$ A sigla RT foi substituída por uma imagem equivalente. Entre outras mudanças icônicas, o Twitter também trocou o símbolo de estrela, que indicava "favoritar" um tuíte, pelo símbolo de coração, indicando "gostar". Os efeitos dessas mudanças são discutidos em detalhe em Bucher e Helmond (2017).
} 
usuários interagem com outras vozes em busca de objetivos e agendas sociopolíticas comuns, no que Zago e Batista (2011) chamam de ativismo digital.

Característica do engajamento interacional, a responsividade é um elemento-chave do trabalho discursivo. Ao projetarmos interlocutores (reais ou virtuais) na interação, incitamos sua responsividade, em um processo essencialmente dialógico (BAKHTIN, 1981). O Twitter pode ser entendido como exacerbador dessa atitude responsiva, já que a simples ação de curtir e/ou de retuitar uma mensagem pode ser uma atitude responsiva, ainda que nada tenha sido propriamente dito. Isso se associa ao fato de os gêneros digitais estarem infiltrados em nosso cotidiano, oferecendo-se como uma maneira de compartilharmos nossa realidade diária, o que Schmidt (2014) chama de personal public: uma publicização pessoal e autorizada pelo usuário, feita de acordo com critérios estabelecidos pelo usuário. Em reflexão semelhante, Zappavigna (2012) ${ }^{8}$ afirma:

Nossas experiências rotineiras nunca estiveram tão sujeitas à disseminação em massa, em tempo real, como hoje. Os microblogs nos proporcionam um fórum para que essas experiências cotidianas possam ser transmitidas quase que instantaneamente, para compartilhar um momento positivo ou para suprir a necessidade humana de reclamar (ZAPPAVIGNA, 2012, p. $37)$.

O tempo é outra importante variável no microblog, que tende a priorizar o presente ao incentivar a disseminação de conteúdo no momento real de produção. Específicos do Twitter, os T'T, por exemplo, não apresentam qualquer marcação visível de tempo, o que encaramos como um indício da efemeridade constitutiva das mídias sociais. $\mathrm{O}$ acesso à data de qualquer TT não visualizado em tempo real requer ferramentas externas, como as gratuitas Tweet 247 e TrendoGate, ou a Socialert, que é paga. A interconexão com APIs (Application Programming Interface) é típica das redes sociais e muito valorizada no Twitter (SCHMIDT, 2014), como veremos com as hashflags.

\section{Entendendo os emojis}

A relevância dos emojis nas atividades humanas não deve ser subestimada. Diferente do que previa o senso comum, os emojis estão longe de ser um simples modismo. Por fazerem parte de nossa comunicação diária on-line, de forma simples e direta, são cada vez mais usados fora da interação nas mídias sociais. No ambiente digital, a confluência dos modos semióticos e as affordances das tecnologias agenciadas formam um intrincado processo multimodal altamente dinâmico, dotado de mudanças contínuas, dada a natureza mais híbrida e mutável da comunicação on-line. Este é o espaço em que os emojis nascem.

Diferentes do Netspeak, que em geral adapta-se às línguas e se centra nas convenções simbólicas próprias da fala e escrita, combinando-as de maneira criativa (cf. CRYSTAL, 2001, 2011), os emojis tendem a ser mais universais, por não se vincularem a um sistema linguístico específico (EVANS, 2017), em princípio. Por outro lado, como elemento simbólico, emojis são pontos de acesso multifacetados e naturalmente polissêmicos, que nos levam a complexos repositórios de informações conceituais (EVANS, 2017), de modo que sua

\footnotetext{
8 Todas as citações diretas aqui incluídas foram traduzidas pelos autores deste artigo.
} 
compreensão se faz mais eficiente na associação a outros elementos linguísticos (DANESI, 2017; EVANS, 2017; STANLAW; ADACHI; SALZMANN, 2018).

Danesi (2017) explica que os emojis são frequentemente usados para suprir elementos indisponíveis na interação online síncrona ou assíncrona, como entonação, gestos e expressões faciais. Nos enunciados, podem atuar como pontuação e/ou como partículas de final de frase. $\mathrm{Na}$ análise do autor, essa "gramática" dos emojis se revela em três funções básicas, quais sejam: 1) sintática: aplicados como pontuação gráfica; 2) semântica: substituindo itens lexicais; e 3) enfática: usados para representar emoções e reforçar efeitos de sentido indicados verbalmente, inseridos junto à emoção comunicada. Desse modo, a gramática dos emojis é "governada pelo significado dos enunciados" (DANESI, 2017, p. 87) e não pelo sentido global do texto.

Embora muitos emojis sejam universais, vários têm sido desenvolvidos para atender a demandas culturais específicas (cf. GÜLSEN, 2016). Como construtos sócio-históricos, sua eficácia de uso depende do significado atribuído aos símbolos no contexto, considerando a carga semântico-pragmática e as nuances socioculturais projetadas. Segundo Danesi (2017), é improvável que textos coconstruídos com emojis sejam compreendidos de maneira uniforme. $\mathrm{O}$ autor argumenta que mesmo falantes de uma mesma língua podem ter dificuldade para interpretar o uso de algum emoji, devido a suas idiossincrasias. Tudo dependerá do contexto em que o emoji é usado e interpretado, visto que são os usuários das tecnologias digitais e falantes da língua os responsáveis por imbuí-los de sentido (DANESI, 2017; EVANS, 2017). Complementando esse raciocínio, Foss (2005) esclarece:

Nem todo objeto visual é uma retórica visual. O que torna o objeto visual um artefato comunicativo - um símbolo que se comunica e que pode ser estudado como retórica - é a presença de três características. A imagem deve ser simbólica, envolver intervenção humana e ser apresentada ao público com a finalidade de se comunicar com ele (FOSS, 2005, p. 150).

Outro aspecto a ser mencionado é a variação visual dos emojis, explicada pelo uso de diferentes linguagens computacionais nas redes sociais e plataformas digitais. Por exemplo:

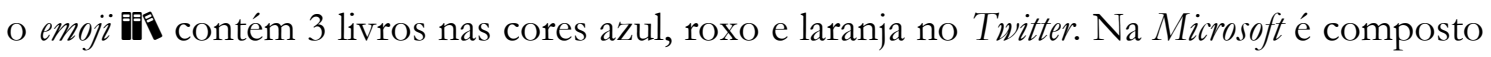
por 4 livros verde, amarelo, azul e laranja, tem contorno preto e sombreamento, propriedade inexistente no emoji do Twitter, que apresenta contorno cinza (figura 2).

Figura 2: versões do mesmo emoji pelo Twitter e pela Microsoft.
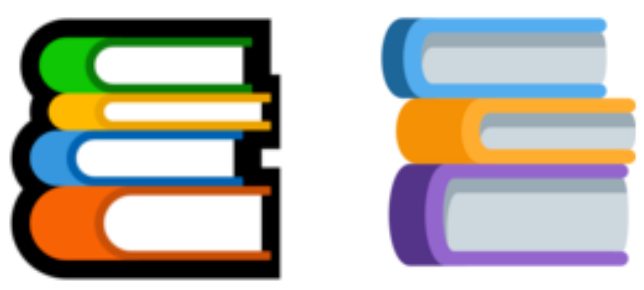

Fonte: Emojipedia.

Considerados por Stark e Crawford (2015) como capital digital, os emojis chamam a atenção não somente por suas características imagéticas ou sua facilidade de uso, mas também por poderem ser manipulados para produzir significados diversos e inesperados, 
que em parte dependem do contexto para total compreensão. É essa uma das justificativas dos autores para o crescente fascínio e adesão à linguagem icônica dos emojis.

\section{Observações metodológicas}

Assim como outros gêneros discursivos emergentes do ambiente virtual, o microblog também é fruto do impacto das tecnologias digitais na vida cotidiana. Essa foi uma de nossas motivações para analisar exemplares de tuítes. Optamos pelo Twitter e não por bate-papos ou serviços de mensagem instantânea (como o Whats $A p p$ ) exatamente para podermos escolher mais livremente textos com emojis diversos, sem o risco de violar questões de privacidade, de modo que os tuítes analisados foram extraídos de contas públicas, em que usuários publicam textos sem restrição de visualização por terceiros, tanto em contas institucionais ou pessoais.

A busca por emojis envolveu diferentes métodos: tema, hashtag listada nos TT do dia e evento, priorizando tuítes com emojis aplicados em associação a outros modos semióticos. Esgotadas essas buscas, inspecionamos as contas que seguimos no Twitter, o que nos levou às hashflags e à seleção final de 40 tuítes com uma diversidade de emojis, cujas funções foram analisadas à luz das categorias propostas por Danesi (2017). Neste artigo, apresentamos 15 dos 40 tuítes, com emojis de função sintática (figuras 3 e 4), semântica (5 a 7) e enfática (8 a 14). A ênfase também se mostra presente nos tuítes que têm hashflags (figuras 17 a 20). A seleção exibida contempla tuítes em português e em inglês; no entanto, em nosso exame completo, analisamos também tuítes em espanhol.

\section{Emojis como elementos de pontuação}

Os emojis no tuíte de @greaymixedsweet fazem a função de aspas, para mencionar um conteúdo musical da banda One Direction, com o primeiro emoji introduzindo a citação de um trecho de uma música, após o autor do tuíte perguntar se os leitores (específicos ou não) sentem saudades da banda. O outro emoji é empregado para sinalizar o fim do trecho musical, da mesma forma que as segundas aspas seriam utilizadas, fechando a fala de outrem. Mesmo se o usuário não tivesse anunciado previamente o tipo de mídia do excerto, o emoji já deixaria claro que se trata de (parte de) uma música, pelo simbolismo das notas musicais, ou mesmo na leitura da hashtag, que contém o nome da banda. 
Figura 3: tuíte com o emoji de notas musicais.

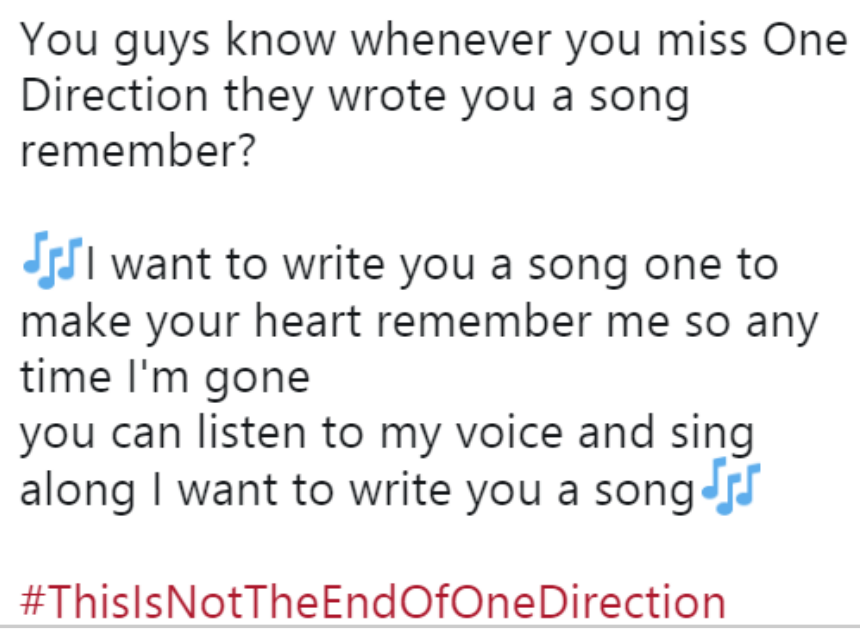

Fonte: Twitter da conta de @greymixedsweet.

$\mathrm{Na}$ figura 3, notamos a casualidade na falta de pontuação na mensagem verbal. Com exceção do ponto de interrogação, os enunciados fluem como se tivessem sido falados, o que também se confirma pelo uso da expressão you guys e pela construção you guys know, típicas da oralidade informal em inglês, em que o verbo auxiliar tende a ser suprimido (nesse caso, o do). A informalidade no uso da língua tem se mostrado característica do Twitter (cf. RISSE et al., 2014), mas não é específica do gênero. Como verificado por Baron (2008), a comunicação na Internet criou uma relação de mais informalidade entre usuários da língua e a prática escrita, na qual conhecer as convenções da escrita e aplicá-las em determinados contextos não implica necessariamente segui-las em outros.

Figura 4: tuíte com o emoji

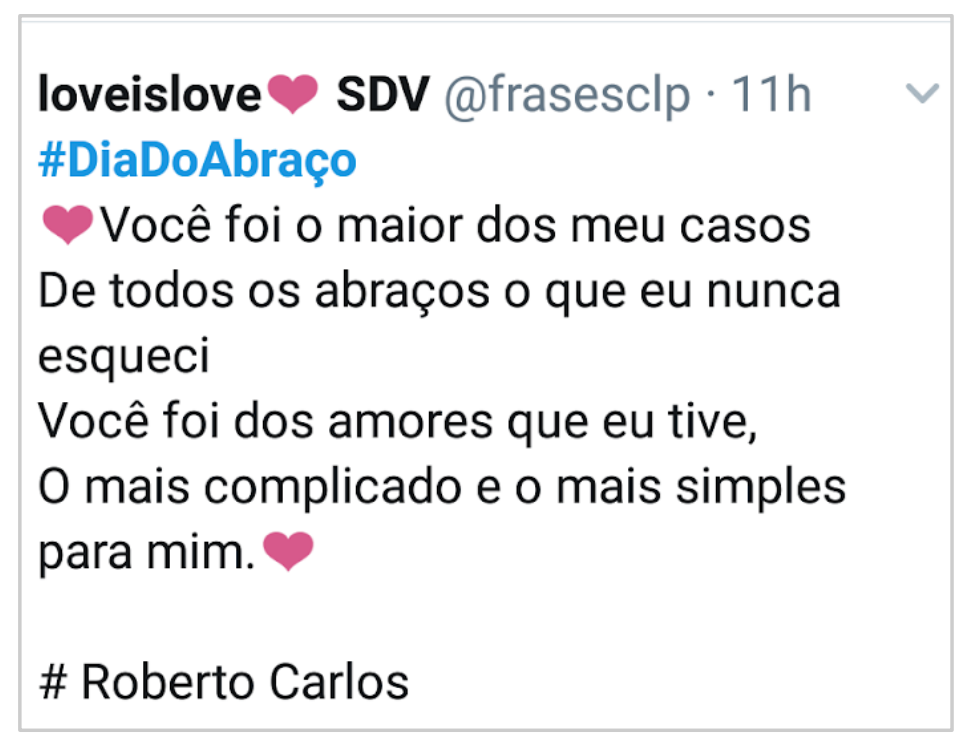

Fonte: Twitter da conta de@frasesclp.

De forma semelhante, o tuíte de @ frasesclp reproduz um trecho da canção Outra $V e z$, interpretada por Roberto Carlos. Segundo o Emojitracker, o $\boldsymbol{\bullet}$ estava entre os mais 
usados no dia da coleta, ocupando o $2^{\circ}$ lugar. Os corações funcionam como pontuação, no lugar de aspas, para representar citação, ao mesmo tempo enfatizando o afeto da usuária à canção e ao Dia do Abraço. O mesmo emoji figura no nome da conta de @frasesclp; mas nesse caso possui outra função: intensifica o significado do nome da usuária (love is love, ou amor é amor).

Uma observação sobre a estrutura do tuíte é o uso incorreto da hashtag \#robertocarlos, em que o símbolo \# e os dois nomes do cantor encontram-se separados e não podem ser lidos computacionalmente pelo Twitter para mapeamento de conteúdo por hashtag. Embora esteja posicionada corretamente ao fim do texto, a função da hashtag se perde devido à configuração incorreta de seus itens. Por fim, vale notar que, nos tuítes reproduzidos nas figuras 3 e 4, os excertos estão divididos por estrofe, como nos originais, mantendo a estrutura das músicas.

\section{Emojis como unidades lexicais}

Figura 5: tuíte com o emoji representando o planeta.

\#tbt to one of the highlights of my life, meeting Baby Spice @EmmaBunton, one of my biggest heroes! I remember feeling so scared with my parents fighting at home and the bullies at school that getting to my bedroom felt like escaping from Earth to a whole new aka Spice World.

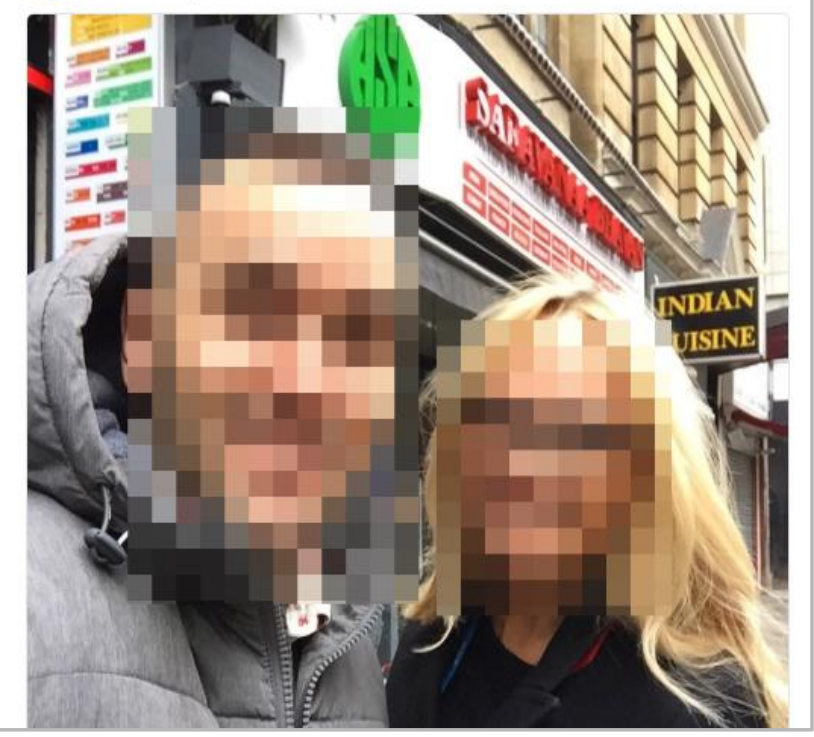

Fonte: Twitter da conta de @jhonnysimoes. 
Como excelente exemplo de personal public (cf. SCHMIDT, 2014), a figura 5 se refere a um \#tbt $t^{9}$ em que o emoji foi inserido como elemento da estrutura frasal, substituindo a palavra world. Sabemos disso não apenas pelo significado do símbolo, mas também porque o usuário diz aka Spice World, especificando a referência e/ou sentido do emoji. Isso quer dizer que o mundo do emoji se refere ao mundo subjetivo do autor, habitado pelas músicas da banda Spice Girls, ideia reforçada pela foto postada, em que o usuário está ao lado de uma das cantoras da banda. Além disso, o conteúdo do tuíte faz menção ao nome artístico da cantora (Baby Spice) e direciona o texto à conta dela com o sinal de arroba.

Figura 6: tuíte com o emoji de abraço.

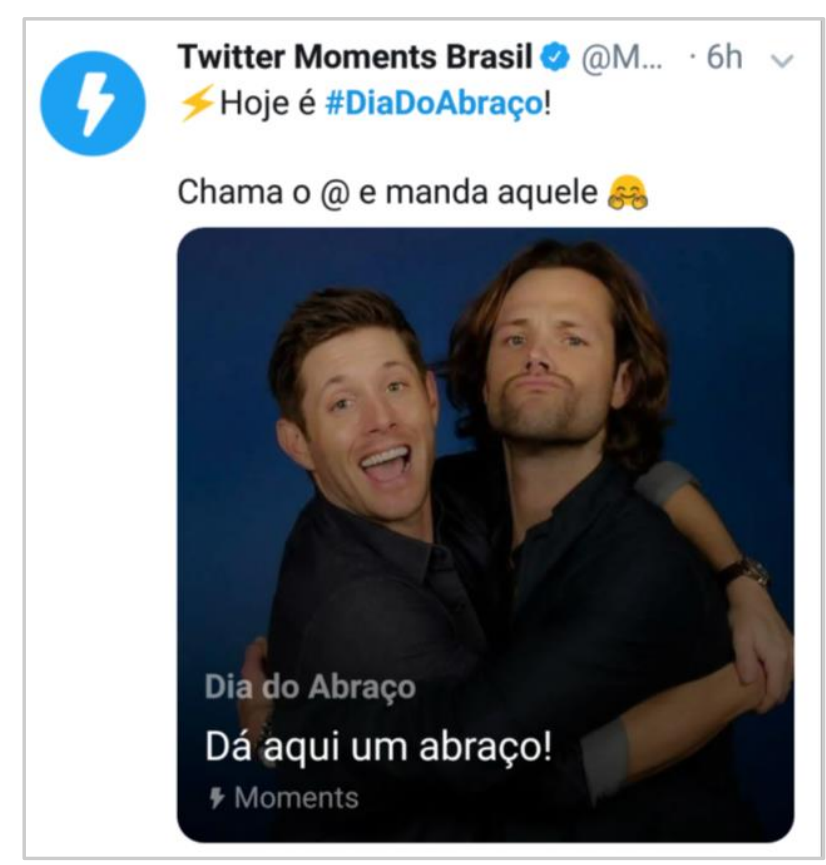

Fonte: Twitter da conta de@momentsbrasil.

$\mathrm{Na}$ figura 6, o emoji encontra-se no nível léxico-gramatical e faz parte da sentença ao substituir a palavra abraço, retendo seu significado-base: a ação de abraçar. Ainda assim, isso não implica uma interpretação isolada, já que é pela associação entre emoji, hashtag, legendas e foto que o leitor recupera semanticamente o item lexical abraşo, levando à construção de sentido. É a junção dos elementos que especifica o emoji, limitando sua natureza polissêmica no contexto do tuíte. O sentido desse emoji também pode ser recuperado pela expressão aquele abraço, muito comum em português, visto que segue o pronome demonstrativo.

Além disso, o tuíte faz uso do marcador dêitico@, como visto em Zappavigna (2012), demonstrando a chamada por interação. O engajamento é criado tanto por essa ação quanto pela escolha da imagem, com duas pessoas se abraçando (os atores são irmãos em uma série de TV americana). Já o emoji de raio é usado para se referir ao tipo de tuíte, os chamados moments, uma funcionalidade recente em que determinados tuítes são selecionados para o usuário, nas categorias notícias, esportes, entretenimento e diversão. No caso da conta Moments Brasil, o usuário já recebe os tuítes curados em seu feed, em relação a conteúdo relevante nesse país.

\footnotetext{
9 Throwback Thursday significa algo como "quinta-feira no fundo do baú" e serve para que usuários da Internet postem às quintas-feiras lembranças ou memórias de algum evento ou experiência marcante.
} 
Figura 7: tuíte com emojis de bandeiras.

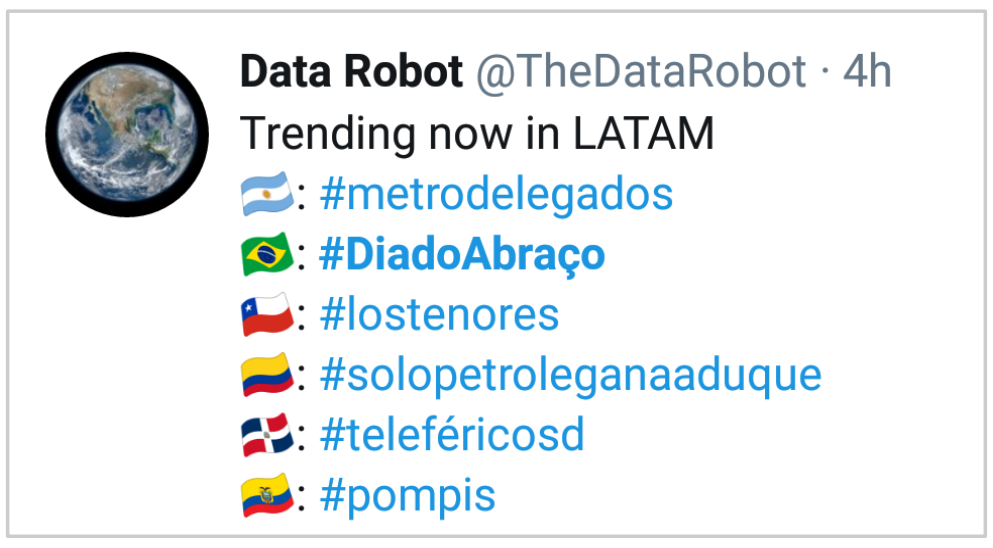

Fonte: Twitter da conta@TheDataRobot.

Um exemplo de emoji de pouca ou nenhuma limitação cultural e/ou contextual são as bandeiras. $\mathrm{Na}$ figura 7 , as bandeiras representadas pelos emojis substituem os nomes dos países cujos TT constam na lista da América Latina, com destaque para \#DiadoAbraço, no Brasil. Além de não exigirem maior contextualização, esses emojis podem auxiliar o leitor o entender as hashtags, que direcionam o usuário a tuítes relacionados. Sabemos que esses emojis operam como itens lexicais devido à presença dos dois pontos após sua inserção e o conteúdo seguinte. Seria como dizer Brasil: \#Diado Abraço, e assim por diante.

\section{Emojis como marcadores discursivos}

Figura 8: tuíte com o emoji chorar de rir.

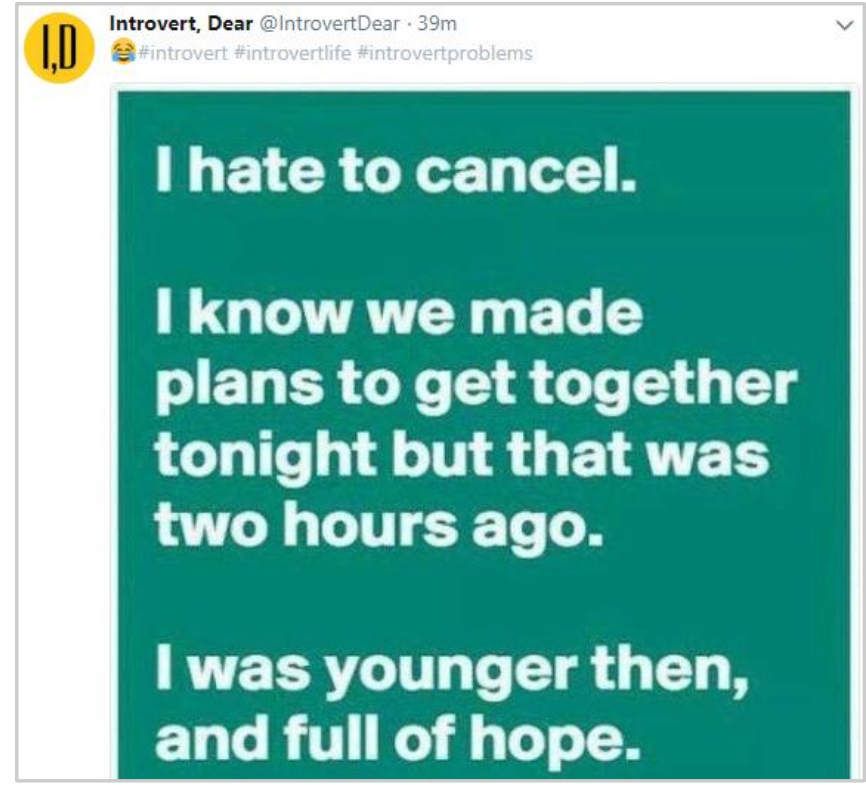

Fonte: Twitterdo@IntrovertDear. 
Em posição antecedente às hashtags \#introvert, \#introvertlife e \#introvertproblems e ao texto, na figura 8, o emoji tem a função de preparar o leitor para o humor do texto da imagem, indicando seu tom cômico. Apesar de uma das hashtags ter carga semântica negativa (\#introvertproblems), o tuíte não é negativo, já que a conotação da palavra problem é irônica, corroborada pela aplicação antecipada do emoji em questão. Tal preparação textual-discursiva pode não ser indispensável para a construção de sentido, mas certamente ajuda a direcionar a leitura, com vistas a sedimentar a reação humorística. Considerando que esse tuíte se dirige a um público específico (pessoas introvertidas, como o nome da conta diz em inglês), é possível que leitores mais extrovertidos não vejam graça no texto, de pronto. Assim, o emoji ajuda a criar a expectativa de humor.

Figura 9: tuíte produzido no Dia do Abraço, em 2018.

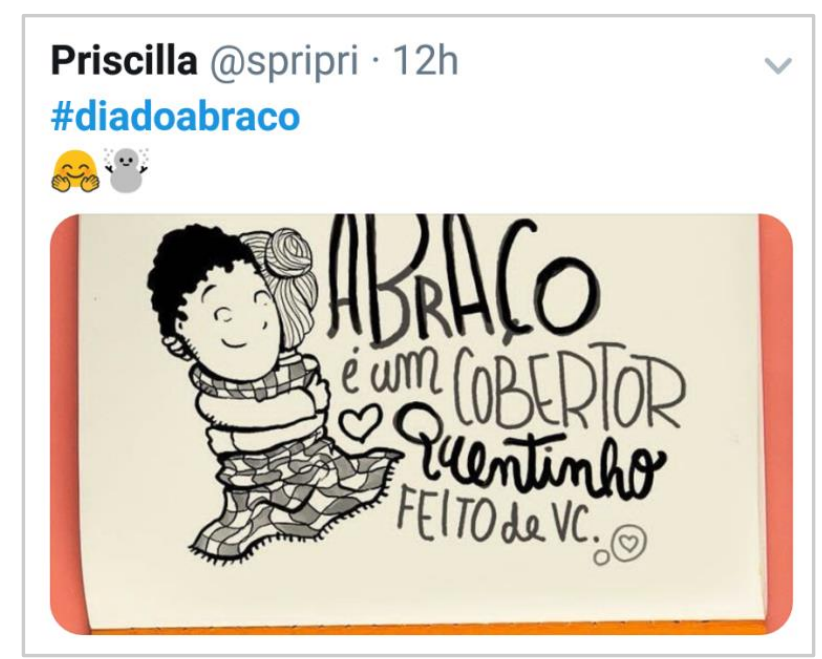

Fonte: Twitter da conta de @spripri.

O tuíte de @spripri contém uma imagem, a hashtag do Dia do Abraço e dois emojis, um representando um abraço e o outro simbolizando um boneco de neve. Esse é um excelente exemplo de limitação contextual: o emoji de boneco de neve é uma referência ao local em que o tuíte foi produzido, não podendo ser compreendido sem seu auxílio. A usuária escreve de São Paulo, onde era inverno no momento em que o tuíte fora produzido, no dia 22 de maio de 2018. Segundo o Climatempo, esse foi um dos dias mais frios naquela região em 2018. Esse fato, unido à mensagem verbal na imagem postada, fazendo referência à ação de se aquecer por um abraço, criam o contexto necessário para que a associação entre um boneco de neve e um emoji de abraço sejam postados juntos no Dia do Abraço.

Nos tuítes das figuras 8 e 9, vemos a emaranhada confluência de semioses em que a imagem dos tuítes constitui-se do modo semiótico imagético, ao mesmo tempo recorrendo ao modo semiótico da escrita em sua composição. Vemos esse "casamento" de linguagens (cf. SANTAELLA, 2003) nos demais tuítes; no entanto, a imagem da figura 9 se faz por desenhos e pela frase desenhada, criando um loop semiótico. 
Figura 10: tuíte com o emoji coração partido.

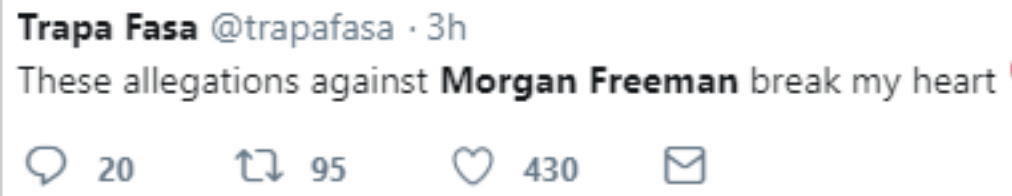

Fonte: Twitter da conta de @ trapafarsa.

Em processo semelhante, mas com sentido diferente, esse tuíte evidencia a desolação do usuário frente às alegações contra o ator Morgan Freeman. O emoji funciona como uma expressão de tristeza, desilusão. Devido à falta de pontuação, o emoji pode também ser entendido como ponto final, em função mais sintática, fazendo parte do período. Já pelo viés intensificador, tem uma função discursiva no tuíte. A aplicação desse emoji segue uma ordem linear de tempo e ação: é a acusação ao ator que gera o sentimento de desolação do usuário e o motiva a produzir o texto com o elemento simbólico e a explicação verbal, complementando o que fora dito.

Figura 11: tuíte com 3 emojis distintos.

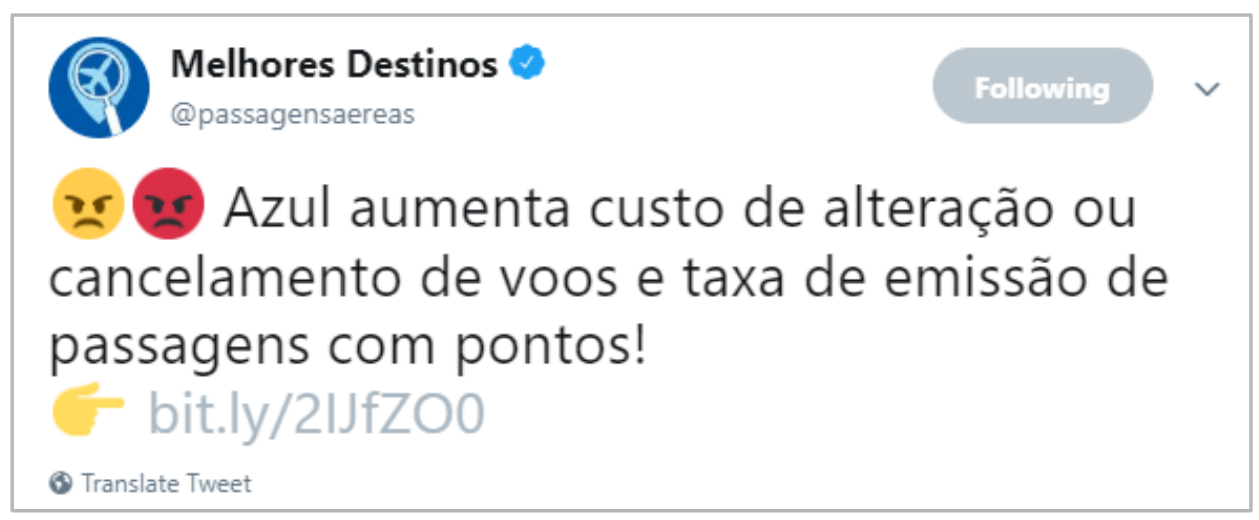

Fonte: Twitter da conta@passagensaereas, do blogue Melhores Destinos.

$\mathrm{Na}$ figura 11, os emojis antecedem a porção verbal do tuíte, indicando aos leitores que a mensagem veicula conteúdo negativo: aumento de taxas por uma empresa aérea. Há dois emojis para indicar raiva e indignação: o vermelho, que intensifica não necessariamente emoji anterior, mas o sentimento de raiva, elevando-a à indignação. Além disso, o tuíte fala de dois aumentos, o que também pode ter motivado o uso de dois emojis. Já o emoji de mão e dedo indicador tem a função de direcionar os leitores para o link no qual poderão ler a notícia em sua totalidade. O link foi encurtado pelo aplicativo Bitly para otimizar o uso do espaço no Twitter, que, na época, aceitava apenas 140 caracteres em suas mensagens. 
Figura 12: tuíte com emojis de apoio à greve dos caminhoneiros.

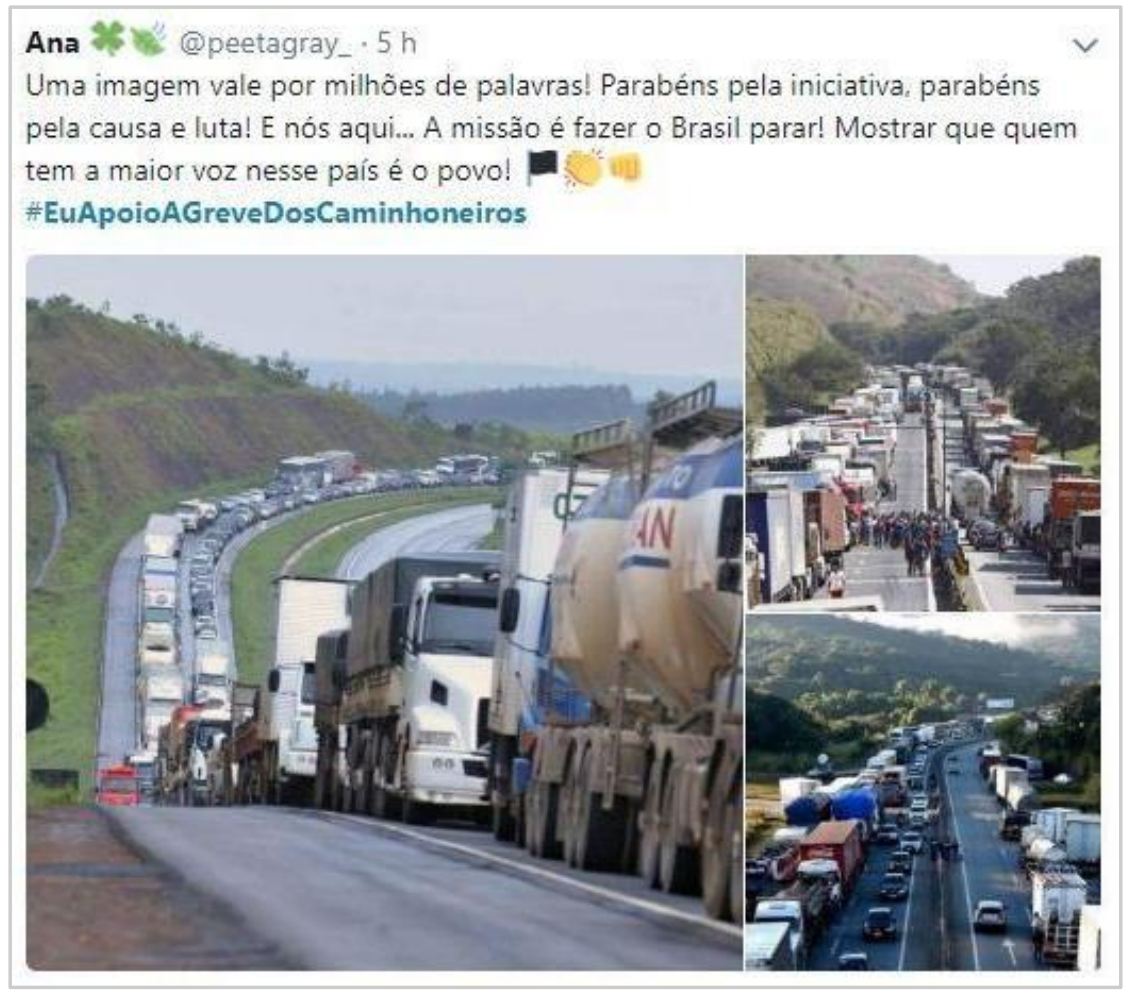

Fonte: Twitter da conta de @peetagray.

Este tuíte foi feito em apoio à greve dos caminhoneiros de 2018 e faz uso de três emojis para expressar emoção: uma bandeira preta, simbolizando a luta da categoria, em oposição à ideia da bandeira branca de paz; mãos batendo palma, indicando que a autora está de acordo com os caminhoneiros, aplaudindo a iniciativa; e uma mão fechada, vista de frente, que mais uma vez denota apoio à greve, intensificando o apreço pelo ato. Os emojis se inserem após o ponto de exclamação, antes da hashtag \#EuApoioAGreveDosCaminhoneiros, o que intensifica as colocações verbais da autora por meio do posicionamento pictórico.

O conteúdo verbal do texto é bem genérico e, sem as imagens dos caminhões, poderia se referir a qualquer outra manifestação com paralisação. Isoladamente, as imagens poderiam remeter a congestionamentos em estradas. Os emojis talvez não perdessem o sentido positivo de luta, se interpretados juntos. Já a bandeira preta seria genérica demais, perdendo seu ponto de referência. Vemos aqui a interdependência dos modos semióticos no Twitter. Só a hashtag não perderia o sentido pretendido, por ser formada por um enunciado completo. 
Figura 13: tuíte com os emojis de choro e corrente.

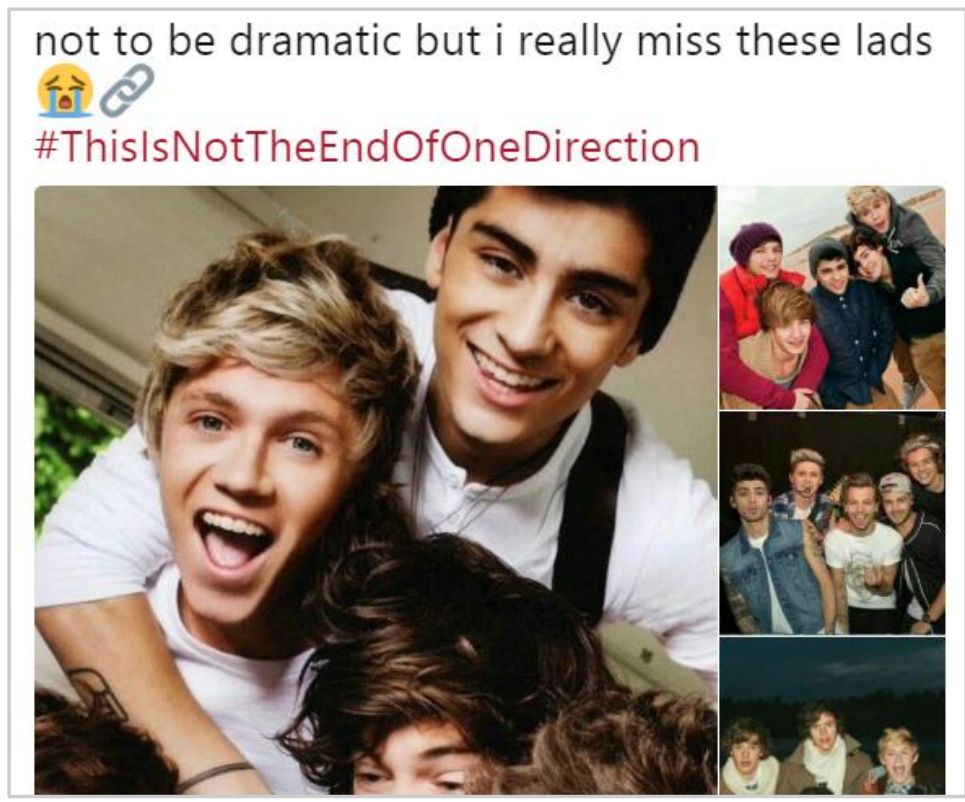

Fonte: Twitter da conta de @frappedhes.

Neste tuíte, o emoji de choro indica o sentimento do autor, a saudade que o usuário tem da banda One Direction e a tristeza que o hiato em que eles entraram lhe causou. O outro emoji utilizado representa uma corrente e pode simbolizar a conexão emocional que @ frappedhes tem com seus ídolos ou que os cantores têm entre si, como banda. O primeiro emoji se associa mais à porção verbal do tuíte, especificamente o adjetivo dramatic e o verbo to miss, enquanto o segundo emoji pode estar mais conectado às imagens incluídas no tuíte, em que os membros da banda aparecem juntos. Esses sentimentos também são intensificados pela hashtag, que no momento de nossa busca figurava nos TT.

A informalidade do ambiente digital pode ser vista não somente pelo tom do tuíte, mas também pelo uso de letras minúsculas em início de frase e no pronome pessoal $I$, que em inglês é sempre maiúsculo e pela palavra lads, que significa algo como "caras", em português.

Figura 14: emoji em uma troca de tuítes.

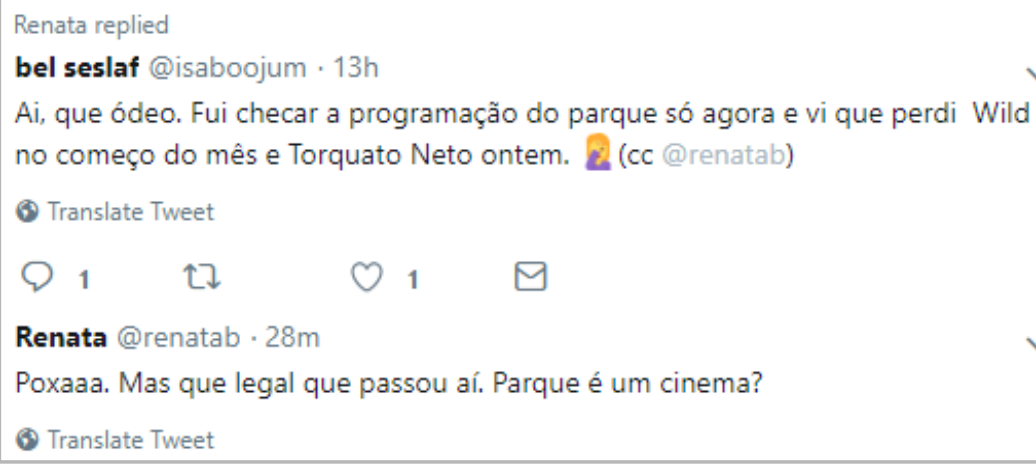

Fonte: Twitterdas contas de@isaboojum e@renatab. 
A troca de tuítes acima contém uma reclamação seguida pelo emoji para expressar a frustração de@isaboojum sobre os eventos perdidos, em tom declarado pela expressão "que ódeo". O tuíte é direcionado à usuária @renatab por CC e a interlocutora demonstra empatia frente à frustração da amiga ao dizer "poxaaa", em que vemos no alongamento do "a" traços da oralidade. Outro traço de informalidade está na inclusão de "Ai", que funciona como uma interjeição, e na grafia da palavra "ódio", escrita como "ódeo".

Figura 15: busca pelo emoji $\mathrm{S}_{\text {no Twitter, partindo da Emojipedia. }}$

Twitter, Inc. [US] | https://twitter.com/search?q= $\mathbf{8} 8$

Fonte: Twitter.

É interessante notar que, segundo a Emojipedia, esse emoji é uma sequência da associação de outros dois: person facepalming + female sign. A pesquisa por esse emoji no Twitter revela exatamente isso no campo de busca (figura 15). Além disso, no Twitter, esse emoji ilustra uma mulher loira, com a mão direita no rosto. Já pela Microsoft, ela é morena e posiciona sua mão esquerda na face. Mais uma vez fica à vista uma malha da computação e das linguagens de programação.

\section{Hashflags}

Segundo Kress (2010), o uso contínuo de um modo semiótico gera mudanças em suas affordances, isto é, em suas possibilidades/potencialidades funcionais. Essas mudanças podem ser percebidas no Twitter na ampliação do limite de caracteres por mensagem, pelas parcerias com terceiros para o desenvolvimento de aplicativos baseados no processamento de dados dos usuários, e pela criação de novos emojis e funcionalidades, como as hashflags, entre outros.

Figura 16: hashflag do filme Hereditário, com o emoji criado para o longa.

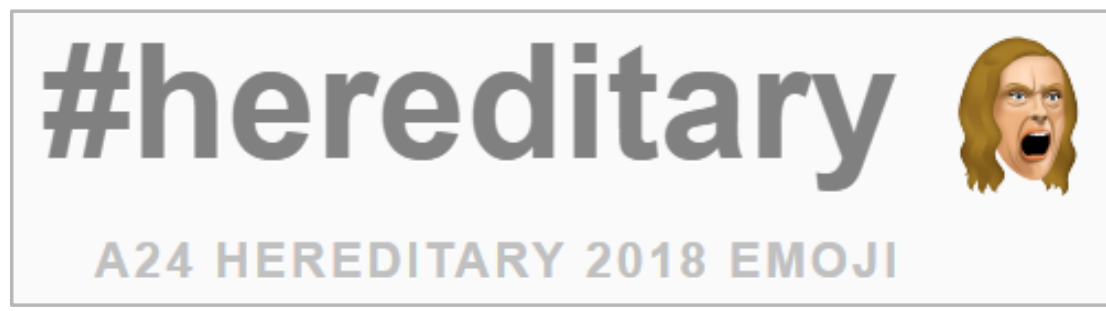

Fonte: Hashtag'd.

Sobre a possibilidade de criação de novos emojis, atualmente há iniciativas pagas que viabilizam produções específicas. Ao contrário do que diz Paiva (2016), esses emojis são feitos não por iniciativa de programadores ou a pedido de usuários, mas sob demanda comercial, para impulsionar grandes campanhas publicitárias. Isso quer dizer que os emojis parecem estar sendo usados cada vez mais de forma estratégica, na busca por visibilidade e/ou aproximação com o público, muitas vezes através de ferramentas estrategicamente agenciadas com o intuito de promover produtos e serviços, como as hashflags. 
Um excelente exemplo de hashflag é o emoji do filme Hereditário, feito para o estúdio A24 pela agregadora Hashtag'd quando da estreia do longa-metragem. Nesse caso, o rosto da protagonista foi reproduzido em expressão de pânico, iconizando em formato digital uma das cenas mais marcantes do filme. Acionado pela hashflag \#hereditary, o emoji foi amplamente divulgado no Twitter, acompanhado ou não por outros. Na figura 17, vemos o emoji após a frase Family is a sacrifice, em referência à família do filme, prototipicamente composta por mãe, pai, filho e filha, assim como no emoji. Portanto, entendemos que a escolha desse emoji se faz tanto por especificidades temáticas do filme quanto pelo conteúdo imagético e verbal do tuíte; ou seja, não é aleatória e evidencia a manipulação simbólica citada por Stark e Crawford (2015).

Figura 17: tuíte com o emoji e a família do filme Hereditary.

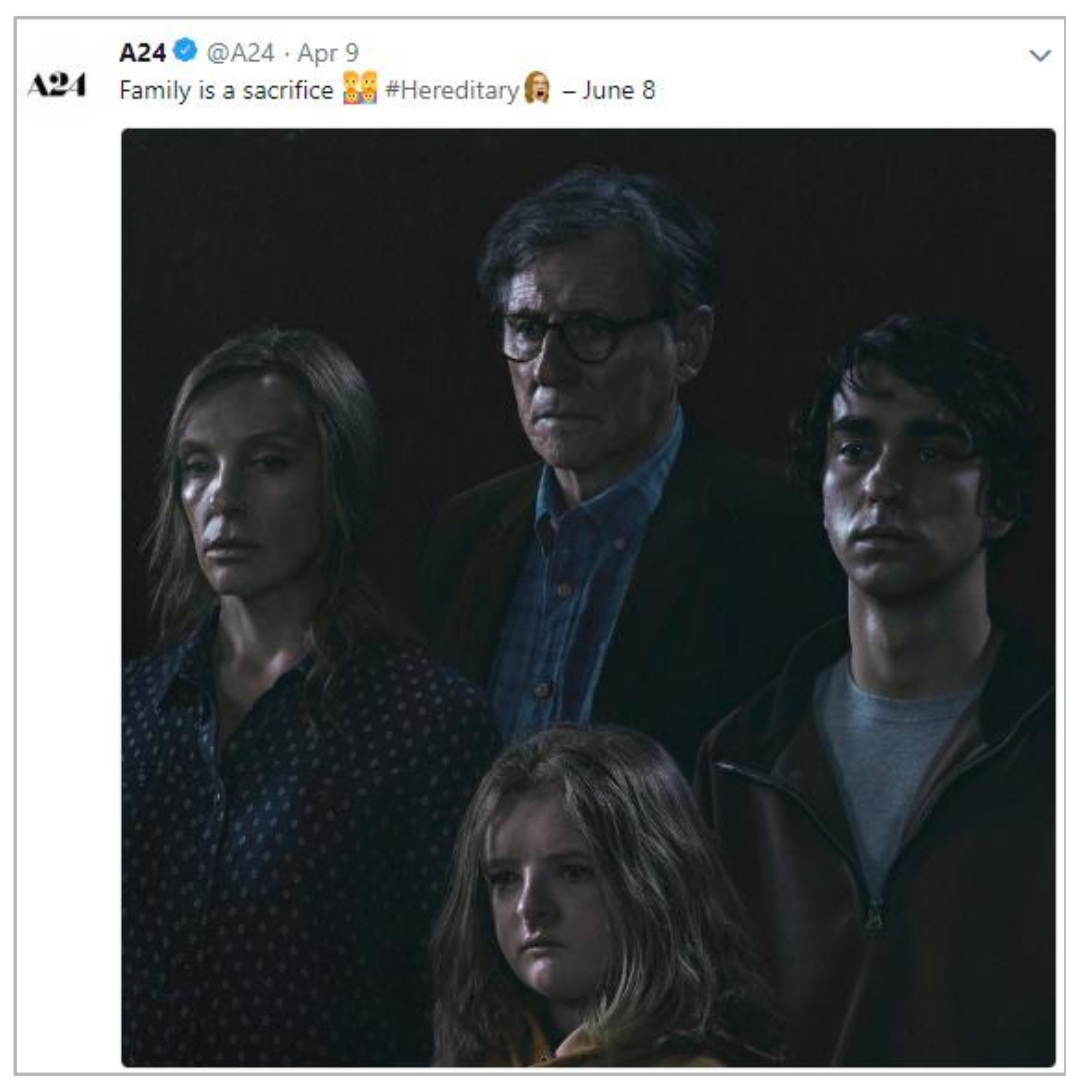

Fonte: Twitter do estúdio @A24.

Em termos linguístico-discursivos, a palavra sacrifice ecoa os sacrifícios que membros de uma família normalmente fazem para o bem geral do núcleo familiar. No caso desse tuíte, no entanto, o artigo indefinido a cria a expectativa de $u m$ sacrifício específico. Por se tratar de um filme de terror, o item lexical sacrifice torna-se ainda mais negativo e o emoji pode também ser visto como intensificador da noção de família, sugerindo esse ser um tema central no filme, ideia já expressa pelo título da obra.

Apesar de não serem acompanhadas no Emojitracker, as hashflags são rastreadas pelas desenvolvedoras. Sua disponibilidade depende do acordado entre cliente e desenvolvedor. Para o filme Hereditário, a hashflag foi feita para ser acionada por qualquer usuário do Twitter de 12 de maio a 10 de agosto de 2018, como visto na figura 18. 
Figura 18: datas de início e fim da hashflag do filme Hereditário.

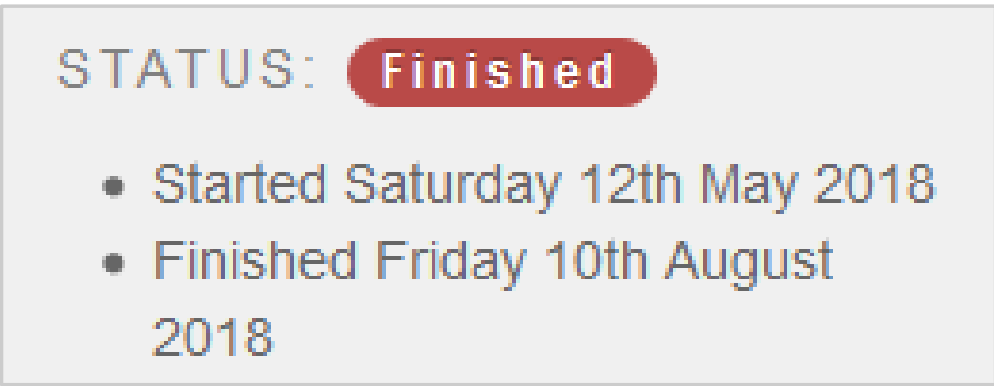

Fonte: Hashtag'd.

Esse é um indício da efemeridade constitutiva das mídias sociais, em que o agora pode durar um minuto, um dia ou mesmo meses, e nossas atividades são arquivadas em caches para a eternidade tecnodigital, paradoxalmente, para serem desenterradas quando oportuno. Dada a importância do Twitter nas áreas empresarial e publicitária (MURTHY, 2013), em que a rede social é considerada uma plataforma séria para a comunicação com as massas (NITINS; BURGESS, 2014), não é de se surpreender que as hashflags tenham ganhado tanto espaço.

Além das desenvolvedoras de APIs, o próprio Twitter se beneficia de novidades como as hashflags. Com o intuito de gerar mais engajamento, personalizar experiências e aumentar o fluxo de dados no Twitter, hashflags como a do filme Hereditário ou a da TwiAge lançam mão da interoperabilidade entre APIs e redes sociais (HELMOND, 2015). A TwiAge, por exemplo, cria um tuíte padrão ao processar os dados do usuário, mediante sua autorização, identificando há quanto tempo ele faz parte do Twitter, informação então inserida junto à bashflag \#MyTwitterAnniversary com o emoji comemorativo (figuras 19 e 20). São iniciativas que visam à personalização computacional da experiência do usuário na rede social, como se vê no Facebook com os testes de personalidade.

Figura 19: hashflag comemorativa do Twitter.

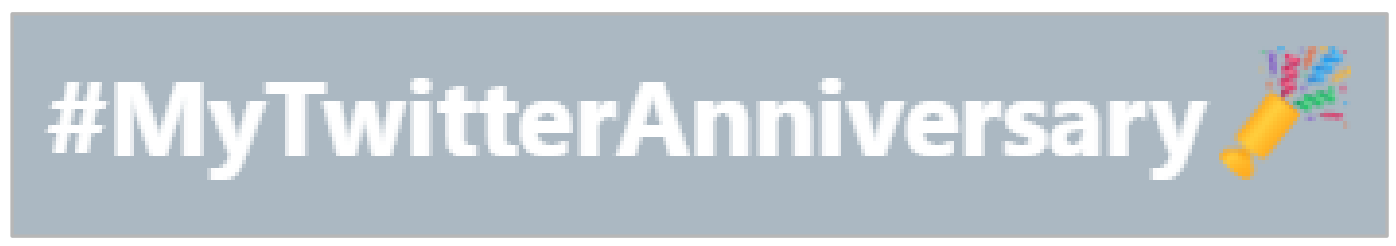

Fonte: TwiAge. 
Figura 20: tuíte com a bashflag \#MyTwitterAnniversary.

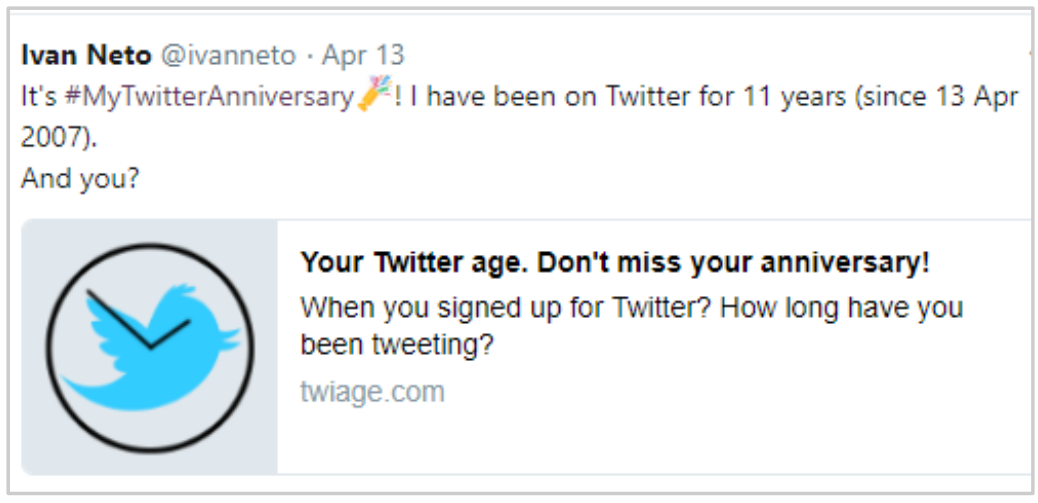

Fonte: Twitter da conta de@ivanneto.

Neste tuíte, o emoji comemorativo encontra-se após o sujeito e o predicado e antes do ponto de exclamação, seguindo a hashtag \#MyTwitterAnniversary. Sua função é de marcador discursivo, enfatizando a construção frasal It's + hashtag. Por ser um tuíte padrão, as únicas variações possíveis são os dados de cada usuário e, por compor uma hashflag, o emoji só pode ser acionado após a inserção da hashtag \#MyTwitterAnniversary, indicando que as hashflags exigem um componente verbal para que o item imagético seja ativado. Na figura 20, seu acionamento é automático pela API.

\section{Considerações finais}

Uma das principais contribuições da sociossemiótica para os estudos da linguagem é o destaque dado a semioses para além dos modos fala e escrita, por meio de investigações sobre multimodalidade, como reflete Jewitt (2013). Apesar da predileção histórica pela fala e escrita em termos de pesquisa linguística, a comunicação humana sempre foi multissemiótica, desde seus primórdios. A sociossemiótica tem como premissa o entendimento de que cada modo semiótico apresenta potencialidades e limitações e que as semioses colaboram entre si para a criação de sentidos (KRESS, 2010; KRESS; VAN LEEUWEN, 2006), evidenciando a relação dialógica que os modos semióticos estabelecem no desenrolar da comunicação.

Neste artigo, vimos que a interdependência entre os modos semióticos no Twitter não deve ser ignorada. Como Danesi (2017) argumenta, ler textos compostos por emojis é uma atividade análoga a decifrar um quebra-cabeças rébus, uma escrita muito comum em moedas da Grécia Antiga e em textos da Idade Média, nos quais o sentido precisava ser desvendado através da associação entre linguagem verbal e não verbal. Dito de outro modo, o que fazemos linguisticamente com os emojis, em termos de produção ou em relação à compreensão textual, não é de todo novo. O que se mostra inovador, no entanto, são as alternativas cada vez mais rápidas e dinâmicas de usar a linguagem no meio virtual.

Nesse sentido, a brevidade típica do Twitter é tanto uma grande vantagem, como nos diz Murthy (2013), quanto um forte indicador do sintetismo e da momentaneidade do fluxo interacional paradoxalmente eternizado nos registros digitais da $W e b$, resultado das igualmente paradoxais relações sociais deste século, em que buscamos conexão e comunhão sozinhos, sem necessidade da presença física. Para equilibrar esse aparente desequilíbrio, lançamos mão e eventualmente transformamos as affordances das ferramentas digitais, 
alterando criativamente as possibilidades de uso da linguagem nas esferas virtuais, das quais nascem emojis, hashtags e hashflags, entre outras que certamente ainda estão por vir.

\section{Referências}

ASKEHAVE, I.; NIELSEN, A. E. Digital genres: a challenge to traditional genre theory. Information Technology \& People, v. 18, n. 2, p. 120-141, 2005.

BAKHTIN, M. Marxismo e Filosofia da Linguagem. Trad. LAHUD, M.; VIEIRA, Y. F. 2 ed. São Paulo: Hucitec, 1981.

BAKHTIN, M. Estética da Criação Verbal. Trad. PEREIRA, M. E. G. G. São Paulo: Martins Fontes, 1997.

BARON, N. S. Always On: language in an online and mobile world. New York: Oxford University Press, 2008.

BARTON, D.; LEE, C. Language Online: investigating digital texts and practices. New York: Routledge, 2013.

BEZERRA, B. Gêneros no contexto brasileiro: questões (meta) teóricas e conceituais. São Paulo: Parábola Editorial, 2017.

BUCHER, T.; HELMOND, A. The affordances of social media platforms. In: BURGESS, J.; POELL, T.; MARWICK, A. (org.). The SAGE handbook of social media. London: SAGE Publications Ltd, 2017.

CONOLE, G.; DYKE, M. What are the affordances of information and communication technologies? ALT-J, v. 12, n. 2, p. 113-124, 2004.

CRYSTAL, D. Language and the Internet. Cambridge: Cambridge University Press, 2001.

CRYSTAL, D. Internet Linguistics: a student guide. London: Routledge, 2011.

DANESI, M. The semiotics of emoji: the rise of visual language in the age of the internet. London: Bloomsbury Publishing, 2017.

EVANS, V. The emoji code. London: Michael O’Mara Books Ltd., 2017.

FOSS, S. K. Theory of visual rhetoric. In: SMITH, K. et al. (org.) Handbook of visual communication: theory, methods, and media. London: Routledge, 2005, p. 141-152.

GAVER, W. W. Situating action II: affordances for interaction: the social is material for design. Ecological Psychology, v. 8, n. 2, p. 111-129, 1996.

GIBSON, J. J. The ecological approach to visual perception. New York: Psychology Press, 2015. 
GÜLSEN, T. You tell me in emojis. In: OGATA, T.; AKIMOTO, T. (org.)

Computational and cognitive approaches to narratology. Philadelphia: IGI Global, 2016.

HELMOND, A. The platformization of the web: making web data platform ready. Social Media + Society, v. 1, n. 2, 2015.

JEWITT, C. Multimodal methods for researching digital technologies. In: PRICE, S.; JEWITT, C.; BARRY B. (org.) The SAGE handbook of digital technology research. Los Angeles: SAGE Publications Ltd., 2013, p. 250-265.

KRESS, G. Multimodality: a social semiotic approach to contemporary communication. New York: Routledge, 2010.

KRESS, G.; van LEEUWEN, T. Colour as a semiotic mode: notes for a grammar of colour. Visual Communication, v. 1, n. 3, p. 343-368, 2002.

KRESS, G.; van LEEUWEN, T. Reading Images: the grammar of visual design. 2 ed. New York: Routledge, 2006.

MARCUSCHI, L. A. Gêneros textuais emergentes no contexto da tecnologia digital. In: MARCUSCHI, L. A.; XAVIER, A. (org.) Hipertextos e gêneros digitais: novas formas de construção do sentido. Rio de Janeiro: Lucerna, 2004.

McCAY-PEET, L.; QUAN-HAASE, A. What is social media and what questions can social media research help us answer. In: SLOAN, L.; QUAN-HAASE, A. (org.) The SAGE handbook of social media research methods. Los Angeles: SAGE, 2017, p. 1326.

MILLER, C. R. Genre as social action (1984), revisited 30 years later (2014). Letras \& Letras. v. 31, n. 3, p. 56-72, 2015.

MURTHY, D. Twitter: social communication in the Twitter age. Cambridge: Polity Press, 2013.

NITINS, T.; BURGESS, J. Twitter, brands, and user engagement. In: WELLER, K. et al. (org.) Twitter and society. New York: Peter Lang, 2014, p. 293-304.

NORMAN, D. A. The psychology of everyday things. New York: Basic Books, 1988.

NORMAN, D. A. The psychology of design. New York: Basic Books, 1990.

ORIHUELA, J. L. Twitter y el boom del microblogging. Perspectivas del mundo de la comunicación, v. 43, p. 2-3, 2007.

PAIVA, V. L. M. O. A linguagem dos emojis. Trabalhos em Linguística Aplicada. v. 2, n. 55, p. 379-399, 2016.

RAMALHO, J. A. Mídias sociais na prática. São Paulo: Elsevier Brasil, 2010. 
RISSE, T. et al. Documenting contemporary society by preserving relevant information from Twitter. In: WELLER, K. et al. (org.) Twitter and society. New York: Peter Lang, 2014, p. 207-220.

SANTAELLA, L. Da cultura das mídias à cibercultura: o advento do pós-humano. Revista FAMECOS, n. 22, 2003.

SCHMIDT, J. Twitter and the rise of personal publics. In: WELLER, K. et al. (org.)

Twitter and society. New York: Peter Lang, 2014, p. 3-14.

STANLAW, J.; ADACHI, N.; SALZMANN, Z. Language, culture, and society: an introduction to Linguistic Anthropology. New York: Westview Press, 2018.

STARK, L.; CRAWFORD, K. The conservatism of emoji. Social Media + Society, v. 1, n. 1, 2015.

ZAGO, G. S.; BATISTA, J. C. Ativismo e agendamento nos trending topics do Twitter: o caso Wikileaks. Contemporânea: Revista de Comunicação e Cultura, v. 9, n. 2, p. 246-259, 2011.

ZAPPAVIGNA, M. Discourse of Twitter and social media: how we use language to create affiliation on the web. London: Continuum International Publishing Group, 2012. 